\title{
Acidic weathering of carbonate building stones: experimental assessment (preliminary results)
}

\author{
Ryszard KRYZA, Marta PRELL, Franciszek CZECHOWSKI \\ Malgorzata DOMARADZKA
}

University of Wroclaw, ul. Cybulskiego 30, 50-205 Poland

Received February 2009; accepted April 2009

Available online June 2009

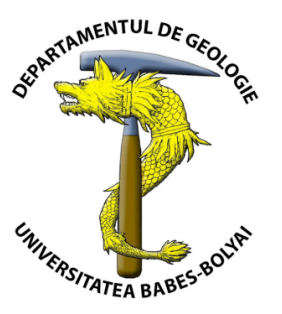

\begin{abstract}
Three types of carbonate rocks, travertine, limestone, and marble have been studied to determine their selected technical parameters (water absorption, resistance to salt crystallization damage) and reaction to experimentally modelled acid rain weathering, imitating the polluted urban atmospheric conditions. The acidic agents present in the natural acid rain precipitation, $\mathrm{H}_{2} \mathrm{SO}_{4}, \mathrm{HCl}, \mathrm{HNO}_{3}, \mathrm{CH}_{3} \mathrm{COOH}$, and the mixture of these acids ("Acid mix"), were tested. The initial stages of acid weathering involve, apart from chemical dissolution, particularly intense physical detachment of rock particles (granular disintegration) significantly contributing to the total mass loss. Travertine was found to be most prone to salt crystallization damage and to acid weathering, and these features should be taken into account especially in external architectural usage of this stone in cold climate conditions and polluted urban atmosphere.
\end{abstract}

Key words: building stones, travertine, limestone, marble, chemical weathering, acid rain, atmospheric pollution.

\section{INTRODUCTION}

Carbonate rocks have been widely used as building stones since ancient times, e.g. in Rome and across the whole Mediterranean. Carbonates are formed in various marine and terrestrial environments; therefore, they are composed of various amounts of matrix, biogenic and nonbiogenic components, and cements. Thus, various petrographic features and petrophysical characteristics determine their resistance to weathering. Recently, the latter is particularly important because of generally increasing atmospheric pollution by acidic agents (Charola and Ware, 2002; Pope et al., 2002). Also, the carbonate rocks are characterized by various porosity and water absorption that control their resistance to frost and salt-crystallization damage (Doehne, 2002; Ondrasina et al., 2002). The solution of the problems of deterioration of these rocks appear very important nowadays due to increasing popularity of the carbonate stones, also in external architectural usage, in all climatic zones, including cold regions with frequent freezing/melting cycles (e.g., in Central and Eastern Europe).

Our study aimed to determine the resistance of three different types of carbonate rocks, namely, travertine, limestone and marble, to the salt-crystallization damage, and more importantly, to the dissolution in acidic solutions with concentrations resembling those from the atmospheric precipitants.

\section{MATERIALS AND METHODS}

The materials used in the acidic weathering experiments were: travertine Travertino Rosso (T) from Iran, limestone *Correspondence: R. Kryza (ryszard.kryza@ing.uni.wroc.pl)
(L) from Morawica (central Poland) and marble (M) from Stronie Slaskie (SW Poland). All these carbonate rocks are commonly used as architectural building and ornamental materials in Poland and other countries in Central Europe. Travertine is a sedimentary carbonate rock, with macroscopically distinct porosity and parallel banded structure (bedding). Limestone is also a sedimentary carbonate rock, but fine-grained and massive, without visible pores and lack of distinct bedding. In contrast, the marble is a metamorphic (amphibolite-facies) crystalline carbonate rock, i.e. marble sensu stricto, with mediumgrained texture and massive, locally (not in the sample) displaying colour banding. The carbonates were studied under the polarizing microscope and using x-ray diffraction (XRD) and differential thermal analyses (DTA) methods. These instrumental analyses confirmed that calcite is the only dominant component in all three samples, where other constituents are in traces, practically negligible. Water absorption was determined according to European Standard EN 13755:2001, and resistance to salt crystallization, following Polish/European Standard PN-EN 12370:2001.

The solutions, resembling the acidity of acid rain, were prepared using: $\mathrm{H}_{2} \mathrm{SO}_{4}, \mathrm{HCl}, \mathrm{HNO}_{3}, \mathrm{CH}_{3} \mathrm{COOH}$ (each acid separately), and a mixture of all these acids ("Acid mix"). The acids selected as agents inducing weathering in the carbonate rocks are common constituents in atmospheric precipitants and their concentration is enhanced in a highly polluted urban atmosphere (e.g., such as in our city of Wroclaw in SW Poland). The two acid concentrations, differing by magnitude, were used in our experiments: $10^{-4}$ and $10^{-3} \mathrm{~mol} / \mathrm{L}$. It is important to note, that the concentration of $\mathrm{H}^{+}$in $\mathrm{H}_{2} \mathrm{SO}_{4}$ solution was twice as high as in the other 
acidic solutions prepared. These concentrations are within the range of the acid rain acidity in the Wroclaw area. The $\mathrm{pH}$ values of the precipitations averaged from four meteorological stations in Wroclaw in 2006 ranged between 4.23 in February, and 6.98 in September (based on the data obtained from the Institute of Meteorology and Water Management in Wroclaw; Prell, 2008 and references therein).

The carbonate samples were cut into regular cubes $2 \times 2$ x $2 \mathrm{~cm}$. The cubes were immersed into $80 \mathrm{~mL}$ of the respective acid solutions and kept for the length of time necessary to achieve $\mathrm{pH}$ increase by value of one. The acid treatment of each cube and in each acid solution was repeated three times. The weighted (total) mass loss, and that calculated from quantified concentrations of dissolved $\mathrm{Ca}^{2+}, \mathrm{Mg}^{2+}, \mathrm{Fe}^{2+}$ and $\mathrm{CO}_{3}{ }^{2-}$ ions, were assessed after each acid treatment. Concentrations of $\mathrm{Na}^{+}$, and $\mathrm{K}^{+}$were also measured but, as appeared very low, were not accounted in quantitative calculations. Microscopic observations (under binocular) and photographs were made before and after each treatment in the acid solutions.

\section{RESULTS}

As expected, the highest porosity has been found in travertine $(8.78 \%)$, much lower in limestone $(6.10 \%)$ and lowest in marble $(2.78 \%)$. Surprisingly, however, the highest water absorption is not in travertine $(0.52 \%)$ but in limestone $(1.61 \%)$, and lowest in marble $(0.04 \%)$. This indicates that pores in travertine are, apparently, not interconnected, isolated and, thus, blocking water permeability, or they are highly macroporous, with very low water absorption potential. However, the pore throat diameter can also be responsible for the capillary uptake of water. The resistance to salt crystallization damage is high for limestone and marble (neglected weight loss) whereas it is significantly lower for travertine (weight loss of c. 0.5 wt.\%; Fig. 1).
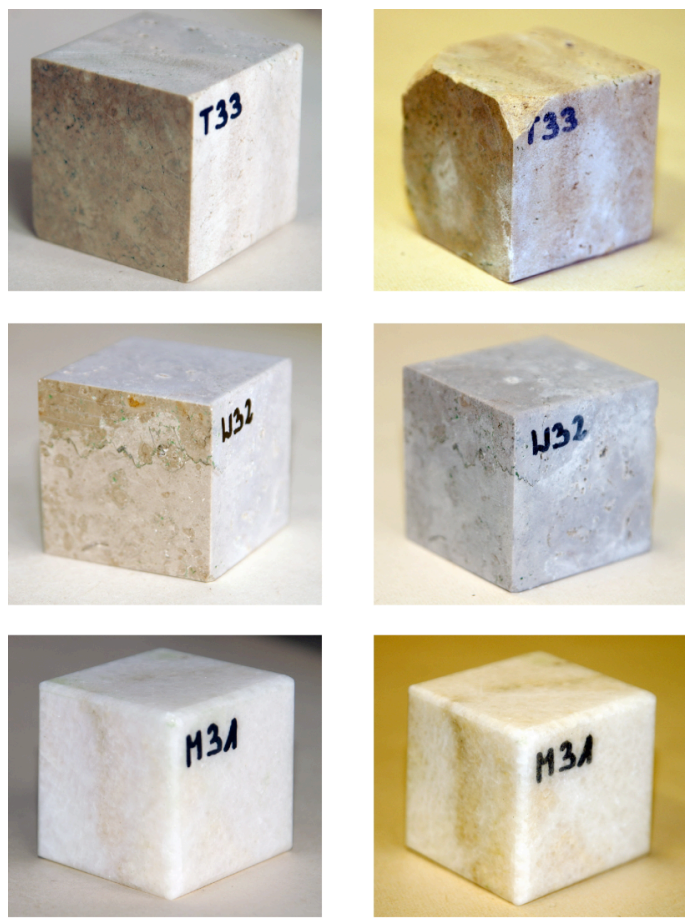

Fig. 1. Resistance to salt crystallization test: samples before (left-hand side column) and after experiments. Note considerable damage in travertine (T33) and much weaker in limestone (W32) and marble (M31).

Studia UBB, Geologia, 2009, 54 (1), 33 - 36
This observation is in apparent contrast with the water absorption data. It may result from a specific pore system in travertine favouring salt crystallisation and, therefore, allowing a more extensive damage. Both these features, i.e. water absorption and resistance to salt crystallization damage, are important factors to be taken into account when using travertine in an external exposition to polluted atmospheric conditions and to intense salt-crystallization processes.

The time necessary to attain $\mathrm{pH}$ value raise by value of one in the lower concentrated acids ranged from 3 to 6 minutes and in the acids of ten times higher concentration was considerably longer, between 10 and 30 minutes. As indicated earlier, the molar concentrations of $\mathrm{H}^{+}$in sulphuric acid solutions were twice higher than in the respective solutions of the other acids. Therefore, the carbonates reaction with the sulphuric acid solutions proceeded nearly twice longer. The three experimental repetitions on each cube, in the acid solutions of a defined concentrations, revealed similar total weight loss on treatment in limestone and marble, whereas much higher loss in travertine. Compared to weight loss in acid solutions of $10^{-4} \mathrm{~mol} / \mathrm{L}$, the total weight loss (summary of dissolution and granular disintegration) in the acids of ten times higher concentration $\left(10^{-3} \mathrm{~mol} / \mathrm{L}\right)$ is not ten times higher as one could expect, but only four to five times higher for strong mineral acids used, e.g. $\mathrm{H}_{2} \mathrm{SO}_{4}, \mathrm{HCl}, \mathrm{HNO}_{3}$ and Acid mix solutions, and twice higher for weak $\mathrm{CH}_{3} \mathrm{COOH}$ acid solution. This can be explained by the observed elevated weight loss, far exceeding the chemical equivalence, in the lower concentration solutions, due to possible chemically-induced physical detachment of mineral particles (granular disintegration) of the rocks that, apparently, were not entirely dissolved in the acidic solutions. For the clarity, it should be mentioned that disintegrated particles, on average below $10 \mathrm{mg}$ contained in $80 \mathrm{~mL}$ of solution, were hardly visible and not quantified separately. The disintegration effect in acid solutions of concentrations $10^{-4} \mathrm{~mol} / \mathrm{L}$ and $10^{-3}$ $\mathrm{mol} / \mathrm{L}$ is, respectively, around twice, and one and a half times higher, in travertine than in limestone and marble. As a consequence, in the acidic solutions of higher concentration (higher chemical reaction capacity with carbonates), the granular disintegration becomes less pronounced. It is manifested in lowering of the ratios of total mass loss to mass dissolved in higher concentrated acids (Fig. 2).

Each run performed in our laboratory weathering experiment on the carbonate rocks broadly resembled twomonth action of the acid rain with acidity fluctuation level reported from the city of Wroclaw (data for 2006: total precipitation $562 \mathrm{~mm} / \mathrm{cm}^{2} /$ year, $\mathrm{pH}$ between 4.23 and 6.98 ; Prell, 2008 and references therein). This conclusion is rationalised on the following reasoning: the total amount of acid solution used for each cubic sample $=3 \times 80 \mathrm{~mL}=240$ $\mathrm{mL}$; the external surface of cubic sample $=2 \times 2 \times 6=24 \mathrm{~cm}^{2}$ (here we ignore porosity); consequently, solution volume per square $\mathrm{cm}$ is $40 \mathrm{~mL} / 24 \mathrm{~cm}^{2}=10 \mathrm{~mL} / \mathrm{cm}^{2}$; an approximate annual precipitation in Wroclaw $=60 \mathrm{~mL} / \mathrm{cm}^{2} /$ year; $10 / 60=$ $1 / 6$ of a year, i.e. two months precipitation.

The total mass loss in the three types of carbonate rocks studied, recalculated into $\mathrm{g} / \mathrm{m}^{2} /$ year, is shown in Fig. 3. The respective diagrams indicate mass loss fractions in total mass loss caused by chemical dissolution (latticed bars) and possible granular disintegration (dashed bars - evaluated from total mass loss by subtraction of chemical dissolution mass) of the stones. The estimations shown in Fig. 3 should 
be considered as rough approximations, knowing that real acid rain weathering is influenced by a range of factors, which were not taken into account in our laboratory experiment (for instance, selective and variable exposition of stone surface to atmospheric agents, and many others).

Even if no distinct changes were observed comparing the photographs and binocular observations (magnification 20x) of the experimental cubic samples before and after treatment by the acid solutions, the total weighted mass loss and composition of the resultant solutions quantitatively resemble the chemical alteration during the experiments.
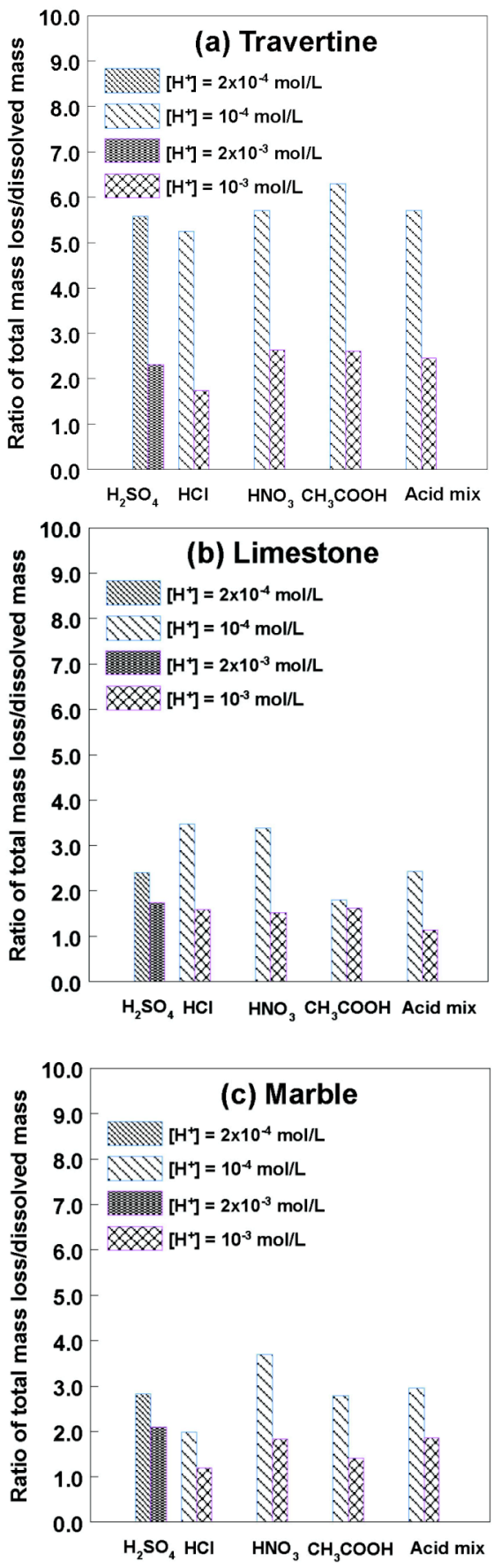

Fig. 2. Ratio of total mass loss (weighted) to dissolved mass (calculated from the analytical data on concentration of dissolved ions) after treatment in the acidic solutions of: (a) travertine, (b) limestone and (c) marble. Note significantly higher ratios (i.e. higher total mass loss compared to values of mass dissolved) after treatment with the lower concentrated solutions (left-hand side bars), which is, most likely, due to enhanced granular disintegration at an initial stage of carbonate acidic dissolution.
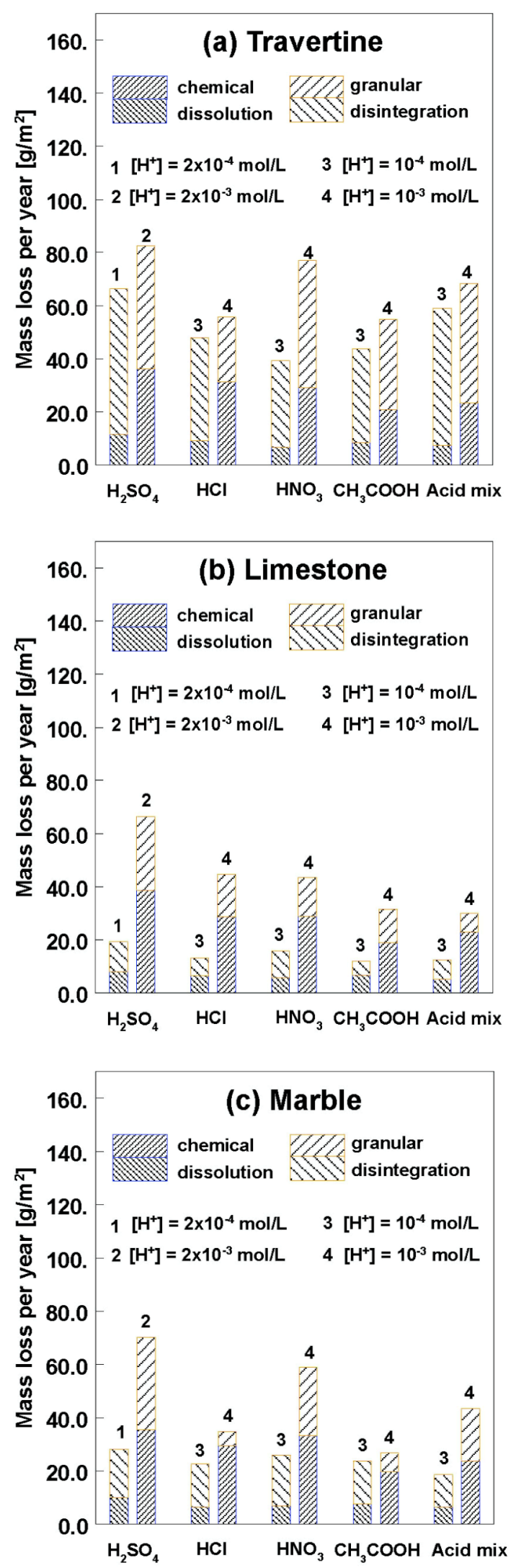

Fig. 3. Total mass loss (full height of the bars) in: (a) travertine, (b) limestone and (c) marble, approximated for one year acid rain weathering with the acids concentration within a range resembling atmospheric acidity conditions of the city of Wroclaw.

Contributions of granular disintegration (dashed upper parts of bars) compared with chemical dissolution (lattice lower parts of

bars) to total mass loss are higher during initial stage of acid weathering (represented by left-hand side bars) in the laboratory experiments.

Studia UBB, Geologia, 2009, 54 (1), 33 - 36 


\section{CONCLUSIONS}

Summing up, the results indicate that there are limestones (e.g. some sedimentary sensu stricto limestones, such as our sample L) that appear to be less resistant to atmospheric freezing/melting damage compared with travertine (T), probably due to the presence of isolated, not interconnected, pore system in the latter. Travertine is most prone to saltcrystallization damage and to chemical weathering caused by acid solutions, compared with both limestone and marble. The acid agents studied show comparable activity towards chemical digestion of the carbonates. However, travertine appears most prone to acidic weathering. Particularly at the initial stage of weathering, apart from chemical dissolution, granular disintegration significantly contributes to the total mass loss of the stones. As could be expected, the higher the concentration of acid, the longer time of its action and the higher final weight loss of the carbonate rock. Our results revealed that the chemical dissolution of the carbonate rocks is not much dependent on the type of rock or the kind of acid, however, the granular disintegration significantly depends on both the type of carbonate and the acid concentration.

The laboratory modelled weathering processes carried out in our study are simplified but they most likely approximate general trends of natural weathering in polluted atmospheric conditions and provide at least semiquantitative estimates of the acid rain-induced weathering rates.

Acknowledgements: The study was supported from Wroclaw University internal grants: 2022/W/ING and 1017/S/ING.

\section{R E F E R E N C E S}

Charola, A.E., Ware, R. 2002, Acid deposition and the deterioration of stone: a brief review of a broad topic. In: Natural stone, weathering phenomena, conservation strategies and case studies (Siegesmund, S., Weiss, T. \& Vollbrecht, A., Eds.). Geological Society Special Publication, 205: 393-406.

Doehne, E. 2002, Salt weathering: a selective review. In: Natural stone, weathering phenomena, conservation strategies and case studies (Siegesmund, S., Weiss, T. \& Vollbrecht, A., Eds.). Geological Society Special Publication, 205: 51-64.

Ondrasina, J., Kirchner, D. \& Siegesmund, S. 2002, Freezethaw cycles and their influence on marble deterioration: a long-term experiment. In: Natural stone, weathering phenomena, conservation strategies and case studies (Siegesmund, S., Weiss, T. \& Vollbrecht, A., Eds.). Geological Society Special Publication, 205: 9-18.

Prell, M. 2008, Weathering of selected sedimentary rocks used as building stones. Unpublished MSc Thesis. University of Wroclaw, Institute of Geological Sciences, Department of Mineralogy and Petrology, $132 \mathrm{p}$.

Pope, G.A., Stavash, J.M. \& Walker, J.C. 2002, Correlation of acid wet deposition with trends in stone deterioration at the local scale. In: Understanding and managing of stone decay (Prikryl, R., Viles, H.A., Eds.), SWAPNET 2001, Charles University in Prague, The Carolinum Press, p. 297-316. 